\title{
Stereotactic Body Radiotherapy of a Solitary Metachronous Sphenoid Metastasis from Renal Cell Cancer: A Case Report
}

\author{
Charles Marchand Crety Estelle Vigneau Camille Invernizzi \\ Department of Radiotherapy, Institut Godinot, Reims, France
}

\section{Keywords}

Renal cell carcinoma - Paranasal sinuses - Neoplasm metastasis - Radiotherapy $\cdot$ Stereotactic body radiotherapy

\begin{abstract}
Nasosinus metastases from kidney cancer are an unusual clinical presentation although some cases are reported in the literature. Among these cases, sphenoidal metastases are even rarer. Here we report a case of lone sphenoid metastasis in patients with papillary renal cell cancer. Eight months after radical nephrectomy, the patient presented with progressively worsening diplopia. Magnetic resonance imaging showed a mass in the right sphenoid sinus. Histopathological examination of the biopsy sample confirmed diagnosis of sinonasal metastasis from papillary renal cell carcinoma. The patient was declined for surgical management and received stereotactic body radiation therapy. Reassessment MRI at 4 months showed a complete response of the treated sphenoid lesion.

\section{Introduction}

Renal cell carcinoma (RCC) accounts for about 3\% of all malignant tumors and $20-30 \%$ of all patients with RCC are diagnosed with metastatic disease. Surgery is actually the only known curative treatment for localized disease. Surveillance after surgery for RCC is important because approximately $20-50 \%$ of patients undergoing nephrectomy will have a relapse and develop metastatic RCC $[1,2]$. Among these patients, two thirds will recur within the first year. The subset of these patients who develop lone metachronous metastasis has the greatest chance to achieve long-term survival [3]. RCC is the most frequent primary tumor to metastasize to the sinonasal region. However, metastasis to the sphenoid sinus is still very rare and

\section{Karger}




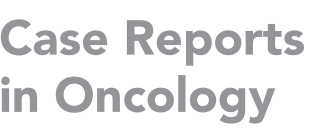

Case Reports

Case Rep Oncol 2021;14:269-273

\begin{tabular}{l|l}
\hline DOI: $10.1159 / 000513743$ & (c) 2021 The Author(s). Published by S. Karger AG, Basel
\end{tabular} www.karger.com/cro

Marchand Crety et al.: Stereotactic Radiotherapy of Sphenoid Metastasis from Renal Cancer

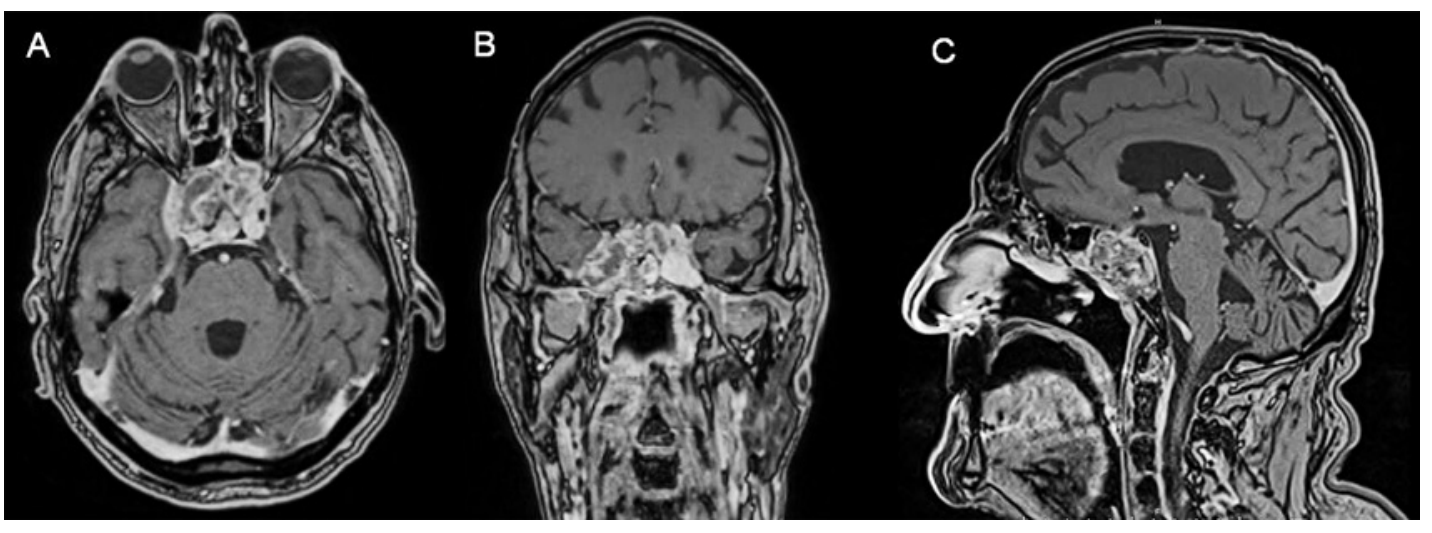

Fig. 1. Axial (A), coronal (B), and sagittal (C) T1-weighted gadolinium-enhanced MRI (magnetic resonance imaging) showing a 36-mm heterogeneous mass from the right sphenoid sinus, invading the cavernous sinus and parasellar regions, encompassing the internal carotid artery and displacing the inner face of the right temporal lobe.

the most common tumor sites from which sphenoid metastases arose seem more likely to be the prostate and the lung. Due to the hypervascularity of the primary tumor, epistaxis is the most common sign in such a condition. Nonspecific symptoms such as headache, facial pain, visual changes, and single or multiple cranial neuropathies may also occur [4, 5]. Surgery appears to be the best therapeutic approach in this situation. Although conventional radiotherapy appears to have a limited impact on the local control of these sphenoidal metastases, it may still be offered in the case of inoperable tumors to relieve symptoms [4, 6]. As stereotactic body radiotherapy (SBRT) demonstrated similar outcomes compared with surgery in various cancer sites, this may seem like a good alternative approach for the treatment of such a lesion. However, to our knowledge, no studies mentioned the use of SBRT in such a situation. Here is thus the first case of a sphenoid bone metastasis treated by SBRT.

\section{Case Presentation}

A 75-year-old male patient presented with a suspicious lesion invading almost all of the left kidney revealed during a CT scan as part of a pulmonary embolism etiological assessment. The medical history included cardiac arrhythmia and diabetes mellitus. He underwent total left nephrectomy, which showed a 8-cm long axis type 2 papillary RCC with lymphatic invasion and thrombosis of the renal vein. Surgical margins were not invaded. There was no adjuvant treatment. Nine months later, the patient progressively suffered from intermittent headache and progressive binocular diplopia. Cranial MRI found a 36-mm mass from the right sphenoid sinus, invading the cavernous sinus and parasellar regions (Fig. 1). Biopsy was performed showing a papillary RCC morphology and immunohistochemistry (cell expression of cytokeratin AE1-AE3, cytokeratin 20, and PAX-8) profile. Surgery was not retained and the patient received SBRT (27 Gy in 3 fractions prescribed to the $80 \%$ isodose line) (Fig. 2), resulting in a complete regression of symptoms within 1 month. First-line anti-angiogenic treatment by sunitinib was started 3 weeks after radiotherapy. At 4 months follow-up, there was no recurrence of symptoms and the cranial MRI showed a complete local response and no detectable residual tumor lesion (Fig. 3.). 


\section{Case Reports in Oncology}

\begin{tabular}{l|l}
\hline Case Rep Oncol 2021;14:269-273 \\
\hline DOI: 10.1159/000513743 & $\begin{array}{l}\odot \text { 2021 The Author(s). Published by S. Karger AG, Basel } \\
\text { www.karger.com/cro }\end{array}$ \\
\hline
\end{tabular}

Marchand Crety et al.: Stereotactic Radiotherapy of Sphenoid Metastasis from Renal Cancer

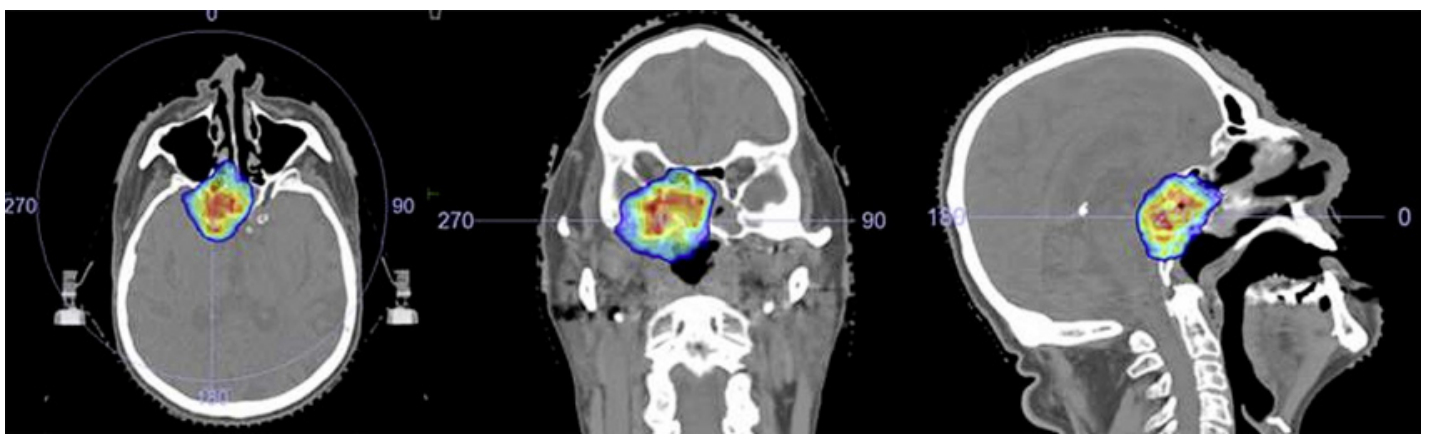

Fig. 2. Stereotactic radiotherapy plan. Radiation planning CT scan of left sphenoid sinus with representative axial, coronal, and sagittal slices. Prescription dose was $27 \mathrm{~Gy}$, three fractions, to the $80 \%$ isodose line.

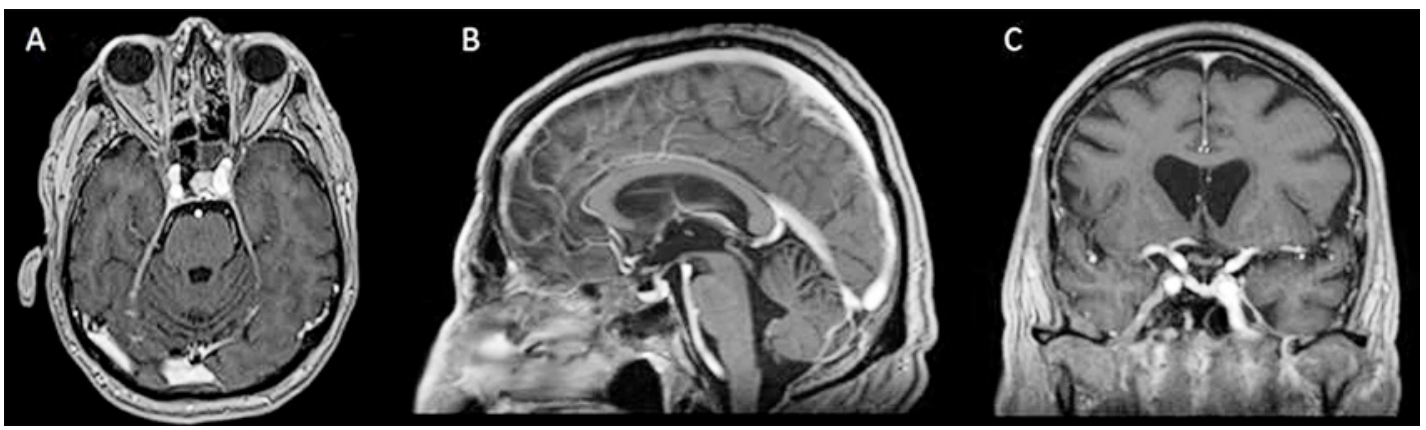

Fig. 3. Axial (A), coronal (B), and sagittal (C) T1-weighted gadolinium-enhanced assessment MRI (magnetic resonance imaging) showing absence of visible residual tumor.

\section{Discussion}

Natural course of RCC commonly results in bone metastases in two-thirds of patients [7]. Although many authors agree that nasosinus metastases most often derive from RCCs, metastases in the particular region of the sphenoid sinus appear to originate from diverse primary neoplastic localizations $[4,8,9]$. In fact, lung and prostate cancer seem to be the two cancers with the highest incidence of sphenoidal metastases [4, 10]. Only a few cases have been reported in patients with colon cancer, melanoma, thyroid carcinoma, and RCC [4, 11-13]. About half of the nasosinus metastases from RCC are metachronous. Furthermore, when it is synchronous such metastasis is revealing of the disease in the vast majority of cases [6]. Regarding management, surgery seems to give the best results. Postoperative radiotherapy does not seem to provide any benefit in preventing the risk of recurrence. Palliative dose radiation therapy appears to be helpful in alleviating symptoms, which was the result in the current case $[4,6]$. Although RCC was originally considered to be a radioresistant tumor to conventional radiotherapy, there is an established biological rationale for the radiosensitivity of RCC to SBRT [14]. An increasing number of studies indeed showed that SBRT is associated with excellent local control and low rates of toxicity for intracranial and extracranial metastases from RCC [15]. However, to our knowledge, no study reported the use of SBRT for sinonasal metastases from RCC. Some cases report the effective and safe use of SBRT for malignant sinonasal melanoma patients $[11,16]$. In our case, we performed a 3D volumetric-modulated 
arc therapy (VMAT) SBRT with VersaHD ${ }^{\circledR}$ Linac (Elekta, Sweden). Prescribed dose was 27 Gy in 3 fractions to the $80 \%$ isodose line. There were no acute adverse effects related to radiotherapy. Reassessment MRI at 4 months showed a complete response of the treated sphenoid lesion.

\section{Statement of Ethics}

This study was approved by the Ethics Review Committee of "Jean Godinot Institute in Reims" and informed consent was obtained from the subject prior to participation. Written informed consent was obtained from the patient for publication of this case report and any accompanying images.

\section{Conflict of Interest Statement}

The authors declare that they have no competing interests.

\section{Funding Sources}

This case report was fully funded by the Godinot Institute.

\section{Author Contributions}

C.M.C. and C.I. wrote the manuscript. C.M.C. performed the radiotherapy. All authors read and approved the final manuscript. C.M.C. is the patient's referring oncologist.

\section{Availability of Data and Material}

The datasets used and analyzed during the current study are available from the corresponding author on reasonable request.

\section{References}

1 Motzer RJ, Bander NH, Nanus DM. Renal-Cell Carcinoma. N Engl J Med. 19 Sept 1996;335(12):865-75.

2 Ljungberg B, Campbell SC, Cho HY, Jacqmin D, Lee JE, Weikert S, et al. The Epidemiology of Renal Cell Carcinoma. European Urology. 1 Oct 2011;60(4):615-21.

3 Janzen NK, Kim HL, Figlin RA, Belldegrun AS. Surveillance after radical or partial nephrectomy for localized renal cell carcinoma and management of recurrent disease. Urol Clin North Am. 2003;30(4):843-52.

4 Mickel RA, Zimmerman MC. The Sphenoid Sinus-A Site for Metastasis. Otolaryngol Head Neck Surg. 1990; 102(6):709-16.

5 Lee SM, Kim YM, Kim BM. Epistaxis as the First Manifestation of Silent Renal Cell Carcinoma: A Case Report with Relevant Literature Review. Iran J Radiol. 2016;13(1):e31208.

6 Bastier P-L, Dunion D, de Bonnecaze G, Serrano E, de Gabory L. Renal cell carcinoma metastatic to the sinonasal cavity: A review and report of 8 cases. Ear Nose Throat J. 2018;97(9):E6.

7 Woodward E, Jagdev S, McParland L, Clark K, Gregory W, Newsham A, et al. Skeletal complications and survival in renal cancer patients with bone metastases. Bone. 2011;48(1):160-6.

8 Bernstein JM, Montgomery WW, Balogh K. Metastatic tumors to the maxilla, nose, and paranasal sinuses. Laryngoscope. 1966;76(4):621-50.

9 Simo R, Sykes AJ, Hargreaves SP, Axon PR, Birzgalis AR, Slevin NJ, et al. Metastatic renal cell carcinoma to the nose and paranasal sinuses. Head Neck. Oct 2000;22(7):722-7. 
10 Petersson F, Hui TS, Loke D, Putti TC. Metastasis of occult prostatic carcinoma to the sphenoid sinus: report of a rare case and a review of the literature. Head Neck Pathol. 2012;6(2):258-63.

11 Albu S, Iulian 0, Necula S. Cutaneous malignant melanoma metastatic to the sphenoid sinus. Ear Nose Throat J. 2014;93(12):E1-3.

12 Nazim-Zygadło E, Dobosz P, Kochanowicz J, Czajecki K. [Metastasis from a colonic adenocarcinoma to the sphenoid sinus]. Otolaryngol Pol. 2005;59(3):429-32.

13 Renner GJ, Davis WE, Templer JW. Metastasis of thyroid carcinoma to the paranasal sinuses. Otolaryngol Head Neck Surg. 1984;92(2):233-7.

14 De Meerleer G, Khoo V, Escudier B, Joniau S, Bossi A, Ost P, et al. Radiotherapy for renal-cell carcinoma. Lancet Oncol. 2014;15(4):e170-7.

15 Kothari G, Foroudi F, Gill S, Corcoran NM, Siva S. Outcomes of stereotactic radiotherapy for cranial and extracranial metastatic renal cell carcinoma: a systematic review. Acta Oncol. 2015;54(2):148-57.

16 Ozyigit G, Cengiz M, Yazici G, Yildiz F, Sezen D, Yildiz D, et al. Robotic stereotactic body radiotherapy in the treatment of sinonasal mucosal melanoma: report of four cases. Head Neck. 2013;35(3):E69-73. 